\title{
O enfoque Ciência, Tecnologia e Sociedade como promoção da Alfabetização Científica e Tecnológica em Museus de Ciências
}

Luciane Jatobá Palmieri luipal@gmail.com

orcid.org/ 0000-0003-0372-0911

Programa de Pós-Graduação em

Educação em Ciências e em Matemática (PPGECM/UFPR), Curitiba, Paraná, Brasil

Camila Silveira da Silva camila@quimica.ufpr.br orcid.org/ 0000-0002-6261-1662 Universidade Federal do Paraná (UFPR), Curitiba, Paraná, Brasil

Leonir Lorenzetti leonirlorenzetti22@gmail.com Orcid.org/ 0000-0002-0208-2965 Curitiba, Paraná, Brasil

\section{RESUMO}

O trabalho objetiva identificar as ações educativas ocorridas em museus de ciências com elementos do enfoque Ciência, Tecnologia e Sociedade (CTS) para a promoção da Alfabetização Científica e Tecnológica (ACT). Por meio de uma pesquisa documental, foram selecionados trabalhos publicados em periódicos nacionais da área de Ensino de Ciências avaliados com Qualis A1 e A2 e nas atas de todas as edições do Encontro Nacional de Pesquisa em Educação em Ciências - ENPEC. Os trabalhos apontam para a importância de o Ensino de Ciências utilizarem os estudos CTS para atingir uma efetividade na ACT e a necessidade de estreitar relações entre museu e escola, pois essa última instituição não tem condições de proporcionar a seu público todas as informações científicas necessárias para a compreensão do mundo atual e os museus de ciências podem contribuir na formação crítica dos cidadãos com relação as questões sobre Ciência e Tecnologia (C\&T). Sinalizamos a carência de pesquisas e a necessidade de reflexão e problematização sobre a educação CTS no campo fértil dos museus de ciências.

PALAVRAS-CHAVE: ACT. CTS. Museus de Ciências. Produção Acadêmica. 


\title{
INTRODUÇÃO
}

Os pesquisadores em Educação das Ciências afirmam a necessidade de um olhar diferenciado ao ensino pautado pela criticidade e desenvolvimento constante exigido pela sociedade contemporânea formada pelo avanço científico e tecnológico desenfreado. De acordo com Schnorr e Rodrigues (2015, p. 32):

\begin{abstract}
Em diversas disciplinas, tais como Física, Química e Biologia, essas competências não são propícias a uma Ciência apresentada de forma tradicional, compartimentada e distante da realidade dos educandos, já que dificulta os processos de ensino e aprendizagem, distanciando teoria e prática. Desse modo, prioriza-se um processo que conjugue diferentes perspectivas do conhecimento, a realidade dos alunos, a produção científica, também, uma formação de professores que trame e desenvolva temáticas sociais com educacionais, possibilitando efetivas imersões nas comunidades em que se inserem as práticas escolares.
\end{abstract}

Pensando nesse olhar diferenciado para o ensino das Ciências, a partir do final do século XX, os museus de ciências deixam de ser apenas um local de lazer, tornando-se um espaço educativo privilegiado pelos educadores, onde permite a vivência de situações de aprendizagem livres de formalidades. A corrida em busca de avanços econômicos e industriais necessita de empoderamento da cultura científica e tecnológica, e esses ambientes são um espaço social capaz de promover inúmeras formas de aprender a aprender (NASCIMENTO, 2010).

Com o frequente aumento de público, os museus tiveram que corresponder às expectativas da sociedade e de seu interesse por ciência e tecnologia. De acordo com Mingues (2014, p. 78) "[...] é nesse contexto que o papel educativo dos museus de ciências tem seu reconhecimento e o desafio de incorporar ações que levem à possível alfabetização científica por parte do público".

Esses espaços oferecem uma aprendizagem ativa onde o público e os acervos museais possuem uma relevante importância. Diante do cenário atual são feitas inúmeras reflexões sobre como desenvolver projetos científicos pautados no movimento Ciência, Tecnologia e Sociedade voltada para a realidade das escolas brasileiras devido à presença assídua do público escolar nos museus e diante do panorama rotulado de "analfabetismo científico".

Alfabetizados cientificamente são aqueles indivíduos capazes de combinar o conhecimento científico com a habilidade de tirar conclusões baseadas em evidências, de modo a compreender e a ajudar na tomada de decisões sobre o mundo natural e as mudanças provocadas pela atividade humana. Isso significa promover a construção de um conjunto de conhecimentos, entendimentos e habilidades, que são requisitos para uma atuação efetiva na vida cotidiana, tendo em vista a importância da ciência, matemática e tecnologia nos dias atuais (CAZELLI; FRANCO, 2001).

Portanto, esse trabalho tem como objetivo identificar, por meio de uma pesquisa documental, as ações educativas ocorridas em museus de ciências com elementos do enfoque Ciência, Tecnologia e Sociedade (CTS) para a promoção da Alfabetização Científica e Tecnológica (ACT). Apresentamos uma explanação teórica sobre o enfoque CTS e a promoção da ACT, os procedimentos metodológicos, as principais características dos estudos selecionados e as considerações finais. 


\section{O ENFOQUE CIÊNCIA, TECNOLOGIA E SOCIEDADE (CTS)}

As discussões sobre Ciência, Tecnologia e Sociedade (CTS) perduram a mais de cinquenta anos, defendendo inúmeros aspectos, propostas no âmbito educacional com diversos enfoques, envolvendo um ou mais dos três elementos e discursos teóricos diferentes. Segundo Bazzo, Linsingen e Pereira (2003, p. 119):

A expressão 'ciência, tecnologia e sociedade' (CTS) procura definir um campo de trabalho acadêmico cujo objeto de estudo está constituído pelos aspectos sociais da ciência e da tecnologia, tanto no que concerne aos fatores sociais que influem na mudança científico-tecnológica, como no que diz respeito às consequências sociais e ambientais.

O CTS surgiu em países desenvolvidos com o pós-guerra, onde danos ambientais, questões éticas, qualidade de vida em meio à sociedade industrializada, maior participação social nas decisões públicas, serviram de justificativas para pensar em propostas de ensino pautadas nos três pilares. 0 objetivo era a formação de um indivíduo em ciência e tecnologia, de uma maneira mais profícua do que vinha sendo feito no ensino formal de educação (SANTOS; MORTIMER, 2002).

Auler e Bazzo (2001) fazem uma reflexão sobre a ciência e a tecnologia no contexto brasileiro, ou seja, uma sociedade emergida sob um processo de colonização, onde o espírito da Revolução Científica nos séculos XVI e XVII passou despercebido, que nunca incluiu a ciência e tecnologia em suas estruturas sócio econômicas, sempre falhou na formação tecnológica dos brasileiros, priorizando a importação de tecnologia. Esse cenário brasileiro começa a mudar na década de 60 , com a fundação de novas universidades, criação de agências de financiamentos para pesquisa, incentivos para trazer de volta ao Brasil pesquisadores que estavam atuando no exterior, principalmente, na Europa. Porém, com relação à ligação entre a ciência e a sociedade no contexto brasileiro, o trabalho de Auler e Bazzo (2001) também aponta uma desvinculação e que o interesse no progresso científico e tecnológico nem sempre visa o bem-estar da população. Auler e Delizoicov (2006) reforçam a necessidade de uma leitura crítica da realidade e não aceitar qualquer discurso produzido durante o avanço científico-tecnológico, onde são elaborados por personagens sociais interessados na disseminação daquele conteúdo específico.

Um exemplo bastante esclarecedor da delicada relação entre ciênciatecnologia com a sociedade é a extinção da carência alimentar, o aumento da produção de alimentos. A ciência e a tecnologia são capazes de resolver essa problemática, por exemplo, através da biologia molecular, porém, não conseguem interferir na gestão de distribuição desses alimentos; ou seja, a produção pode ser aumentada, mas o acesso a esses alimentos por quem tem necessidade não pode ser solucionado pela ciência-tecnologia (AULER; DELIZOICOV, 2006).

O trabalho de Strieder (2012), na busca por identificar os pressupostos que têm guiado as diferentes abordagens CTS presentes no contexto brasileiro da Educação Científica, indicou que os estudos dessa tríade muitas vezes são esquecidos no âmbito educacional, devido a uma insatisfação com o avanço científico-tecnológico. Ainda de acordo com a mesma autora, o Ensino de Ciências no Brasil possui uma diversidade de abordagens CTS que foi identificada em um 
levantamento nos anais do Encontro Nacional de Pesquisa em Educação em Ciências e nos principais periódicos da área.

Essa diversidade de olhares para as relações CTS é identificada pelos pesquisadores da área, porém, não é o foco de atenção nas pesquisas. As discussões dessa tríade podem emergir a partir de três parâmetros relacionados à: racionalidade científica, desenvolvimento científico-tecnológico e participação social; e são articulados e sustentados por percepções entre o conhecimento científico escolar e o contexto do aluno, questionamentos sobre situações que envolvem aspectos de ciência, tecnologia e/ou sociedade e compromisso social diante de problemas ainda não estabelecidos e que envolvem aspectos CTS (STRIEDER, 2012).

Diante das explanações apresentadas, é possível afirmar a importância da temática na melhoria do Ensino de Ciências brasileiro, o avanço significativo das pesquisas e ressaltar o que Strieder (2012, p. 268) afirma "[...] carência de discussão atualizada de aspectos da função social da ciência no campo CTS - Ensino de Ciências".

\title{
A ALFABETIZAÇÃo CIENTíFICA E TECNOLÓGICA (ACT)
}

O termo Alfabetização Científica possui distintas traduções de acordo com a língua original, sendo a expressão inglesa traduzida como "Letramento Científico" e a expressão francesa e espanhola como "Alfabetização Científica". No presente texto será utilizado o termo Alfabetização Científica, que de acordo com Sasseron e Carvalho (2011, p. 60) “[...] o objetivo desse Ensino de Ciências almeja a formação cidadã dos estudantes para o domínio e uso dos conhecimentos científicos e seus desdobramentos nas mais diferentes esferas de sua vida". As autoras baseiam-se nas ideias de alfabetização de Paulo Freire onde o indivíduo seja capaz de organizar seu pensamento de maneira lógica, com criticidade em relação ao mundo que o cerca e estabelecer conexões desse com a palavra escrita, em busca da construção de novos saberes. Encontramos ainda outros termos como "Enculturação Científica" e "Cultura Científica", designando essa mesma preocupação apresentada acima (MINGUES, 2014).

Já no que diz respeito ao campo da divulgação científica, encontramos os termos "Popularização da Ciência", "Comunicação Pública da Ciência" e "Vulgarização da Ciência". Para Mingues (2014, p. 24):

\begin{abstract}
Em seu conjunto, esses termos são, hoje, comuns, tanto na literatura especializada sobre educação, quanto nos meios de comunicação de massa, para designar as práticas de socialização do conhecimento científico com vistas a promover seu acesso. Embora cada termo dê origem a linhas teóricas distintas, é possivel identificar, em todas, a ideia do domínio, pelos cidadãos, dos conceitos e processos científicos e das relações entre a ciência e a sociedade.
\end{abstract}

Segundo Pérez e Moliní (2004), a expressão divulgação científica é polivalente e pode possuir duas condições: a divulgação da ciência é feita fora do ensino formal/regular e não se destina a formar especialistas. Essa atividade comunicativa apresenta seis funções: informativa (adaptação para uma linguagem mais compreensível, proporcionando a toda sociedade apropriar-se desse conhecimento e conseguir dialogá-lo); educativa (principalmente nos países em 
desenvolvimento ou de industrialização tardia, a comunicação da ciência complementa a educação formal); social (aproximação da ciência e sociedade, fazer o papel de desmistificação); cultural (a ciência é cultura e o conhecimento científico é uma criação do pensamento humano); econômica (mostrar a relação entre ciência, tecnologia e o setor produtivo); política-ideológica (a atividade científica não é ideologicamente neutra).

Fourez (1994 apud SASSERON; CARVALHO, 2011) apresenta algumas habilidades necessárias para considerar uma pessoa alfabetizada cientificamente, sendo elas: utiliza os conceitos científicos e é capaz de integrar valores, e sabe fazer por tomar decisões responsáveis no dia a dia; compreende que a sociedade exerce controle sobre as ciências e as tecnologias, bem como as ciências e as tecnologias refletem a sociedade; compreende que a sociedade exerce controle sobre as ciências e as tecnologias por meio do viés das subsunções que a elas concede; reconhece também os limites de utilidade das ciências e das tecnologias para o progresso do bem-estar humano; conhece os principais conceitos, hipóteses e teorias científicas e é capaz de aplicá-los; aprecia as ciências e as tecnologias pela estimulação intelectual que elas suscitam; compreende que a produção dos saberes científico depende, ao mesmo tempo, de processos de pesquisas e de conceitos teóricos; faz a distinção entre os resultados científicos e a opinião pessoal; reconhece a origem da ciência e compreende que o saber científico é provisório, e sujeito a mudanças a depender do acúmulo de resultados; compreende as aplicações das tecnologias e as decisões implicadas nestas utilizações; possua suficientes saber e experiência para apreciar o valor da pesquisa e do desenvolvimento tecnológico; extraia da formação científica uma visão de mundo mais rica e interessante; conheça as fontes válidas de informação científica e tecnológica e recorra a elas quando diante de situações de tomada de decisões; certa compreensão da maneira como as ciências e as tecnologias foram produzidas ao longo da história.

Apesar do aumento significativo de pesquisas e ações didático/pedagógicas que visam à incorporação do enfoque CTS no ensino de ciências Chassot (2003) aponta que só estaremos alfabetizando cientificamente quando tal abordagem se fizer presente no currículo desde a Educação Infantil até o Ensino Superior. De acordo com Lorenzetti e Delizoicov (2001), a alfabetização científica pode nortear os processos educativos a partir dos anos iniciais, mesmo quando a criança não domina o código escrito e esse contato pode auxiliar no processo de aquisição da escrita futuramente, assim como ampliar sua cultura. Lorenzetti e Delizoicov (2001, p. 9) compreendem a alfabetização científica nos anos iniciais "[...] como o processo pelo qual a linguagem das Ciências Naturais adquire significados, constituindo-se um meio para o indivíduo ampliar o seu universo de conhecimento, a sua cultura, como cidadão inserido na sociedade", e reforçam também que essa atividade é vitalícia, perdura ao longo da vida.

Ainda de acordo com os autores supracitados, a alfabetização científica não pode ser de responsabilidade única e exclusivamente da educação formal. Para Lorenzetti e Delizoicov (2001) essa deve instruir os alunos a como e onde buscar esses conhecimentos científicos, 
As atividades pedagógicas desenvolvidas que se apoiam nestes espaços, aulas práticas, saídas a campo, feiras de ciências, por exemplo, poderão propiciar uma aprendizagem significativa contribuindo para um ganho cognitivo (LORENZETTI; DELIZOICOV, 2001, p. 7).

No trabalho de Sasseron e Carvalho (2011), são apresentados os eixos estruturantes da alfabetização científica que devem ser considerados no momento de elaboração e planejamento de atividades no âmbito formal e não formal. 0 primeiro eixo que deve ser levado em consideração é a compreensão básica de termos, conhecimentos e conceitos científicos fundamentais, onde é necessário trabalhar os conceitos científicos chaves que são utilizados em diversas situações do dia a dia; o segundo eixo é a compreensão da natureza das ciências e dos fatores éticos e políticos que circundam sua prática, mostrando a importância de que a ciência é provisória e resultado da construção humana; o terceiro e último eixo é o entendimento das relações existentes entre ciência, tecnologia, sociedade e meio-ambiente, mostrando a relação desses elementos, visando à compreensão e aplicação dos saberes construído pelas ciências em busca de uma sociedade sustentável.

Portanto, para promover a alfabetização científica e tecnológica é necessário apresentar propostas interdisciplinares, estabelecer parcerias entre a educação formal e não formal, visando à aproximação da ciência e da tecnologia à cultura da população.

\section{PROCEDIMENTOS METODOLÓGICOS}

O estudo realizado se caracteriza como documental, de natureza qualitativa, pois de acordo com Silva et al. (2009, p. 4557) "[...] a pesquisa documental permite a investigação de determinada problemática não em sua interação imediata, mas de forma indireta, por meio do estudo dos documentos que são produzidos pelo homem e por isso revelam o seu modo de ser, viver e compreender um fato social". Os documentos analisados foram aqueles publicados nas revistas nacionais relacionados à área de avaliação "Ensino", com enfoque nas produções sobre Ensino de Ciências.

Outro critério de seleção foi a avaliação junto ao Qualis 2014 da CAPES $^{1}$, onde selecionamos os avaliados em A1 (mais elevado) e A2. A lista das revistas pesquisadas e o período consultado encontram-se no Quadro 1.

Quadro 1 - Revistas consultadas no Portal de Periódicos CAPES.

\begin{tabular}{c|c}
\hline Revista & Periodo Investigado \\
\hline Ciência \& Educação & $1994-2015$ \\
\hline $\begin{array}{c}\text { Ensaio: Pesquisa em Educação em } \\
\text { Ciências }\end{array}$ & $1999-2015$ \\
\hline Investigações em Ensino de Ciências & $1996-2015$ \\
\hline $\begin{array}{c}\text { Revista Brasileira de Pesquisa em } \\
\text { Educação em Ciências }\end{array}$ & $2001-2015$ \\
\hline
\end{tabular}

Fonte: Autoria própria (2017).

O recorte temporal de busca nas revistas foi desde o primeiro número de publicação até o último do ano de 2015, pois a localização dessas produções foi 
realizada no primeiro semestre de 2016, com o objetivo de pesquisa bibliográfica para a Dissertação de uma das autoras.

Buscamos também produções nas Atas do evento mais importante relacionado do Ensino de Ciências, o ENPEC - Encontro Nacional de Pesquisa em Educação em Ciências. Os trabalhos foram localizados nas Atas disponíveis online através do site http://abrapecnet.org.br/wordpress/pt/atas-dos-enpecs/, referente a todas as edições, compreendendo o período entre 1997 a 2015. Os descritores utilizados na busca foram: museu, museus, museu de ciências, museus de ciências, CTS e ACT, os quais apareciam no título ou nas palavras-chave. Em algumas Atas os trabalhos estão divididos por linhas temáticas e nossa busca foi realizada na linha temática de Educação em espaços não formais e divulgação científica (ENF).

Todos os trabalhos foram lidos na íntegra, uma vez que os resumos nem sempre permitem uma compreensão adequada dos mesmos. Depois de feita a leitura, elaboramos uma ficha de análise para registro das informações referentes a cada um dos textos. Os itens contemplados na ficha e que pautaram nossas discussões foram: distribuição dos trabalhos por periódicos e por eventos, autores, título, problema de pesquisa, metodologia utilizada, público alvo, instituição onde foi desenvolvida a pesquisa, referenciais teóricos, ações educativas e sua articulação com CTS e ACT, contribuições e lacunas existentes.

Ao longo da discussão, será utilizado um código para identificar os trabalhos: A (artigo) e T (trabalho completo).

\section{RESULTADOS E DISCUSSÃO}

Como já citado na explanação teórica, para a promoção ampliada da alfabetização científica e tecnológica, que relaciona a compreensão da interação entre CTS, é de extrema importância estabelecer parcerias entre a educação formal e a não formal. Diante dessa afirmação, apresentamos o Quadro $2 \mathrm{com}$ o detalhamento dos trabalhos analisados que foram desenvolvidos no âmbito dos museus de ciências através do enfoque CTS e com o objetivo de propiciar a ACT.

Quadro 2 - Detalhamento dos trabalhos analisados

\begin{tabular}{c|c|c|c|c}
\hline Fonte & Autores & Título & $\begin{array}{c}\text { Código } \\
\text { do } \\
\text { Trabalho }\end{array}$ \\
\hline $\begin{array}{c}\text { Ciência \& } \\
\text { Educação }\end{array}$ & $\begin{array}{c}\text { GOUVÊA, G.; } \\
\text { LEAL, M. C. }\end{array}$ & $\begin{array}{c}\text { Uma visão comparada } \\
\text { do ensino em Ciência, } \\
\text { Tecnologia e Sociedade } \\
\text { na escola e em um } \\
\text { museu de ciência }\end{array}$ & 2001 & A1 \\
\hline $\begin{array}{c}\text { Ensaio: } \\
\text { Educação em } \\
\text { Ciências }\end{array}$ & LEAL, M. C.; & $\begin{array}{c}\text { Narrativa, Mito, Ciência } \\
\text { e Tecnologia: o Ensino } \\
\text { de Ciências na Escola e } \\
\text { no Museu }\end{array}$ & 2002 & A2 \\
\hline I ENPEC & LEAL, M. C.; & $\begin{array}{c}\text { Tecnologia no Ensino de } \\
\text { Ciências: o tempo na } \\
\text { escola e no museu }\end{array}$ & 1997 & T1 \\
\hline
\end{tabular}




\begin{tabular}{|c|c|c|c|c|}
\hline II ENPEC & $\begin{array}{l}\text { LEAL, M. C.; } \\
\text { GOUVÊA, G. }\end{array}$ & $\begin{array}{l}\text { Ensino de Ciências e } \\
\text { Ciência Tecnologia e } \\
\text { Sociedade: Comparando } \\
\text { Perspectivas no Ensino } \\
\text { Formal e Não Formal }\end{array}$ & 1999 & $\mathrm{~T} 2$ \\
\hline VII ENPEC & $\begin{array}{c}\text { CONTIER, D.; } \\
\text { MARANDINO, M. }\end{array}$ & $\begin{array}{c}\text { Construção de atributos } \\
\text { para análise de } \\
\text { exposições CTS em } \\
\text { museus de ciências }\end{array}$ & 2009 & T3 \\
\hline VII ENPEC & $\begin{array}{l}\text { WOLINSKI, A. E. } \\
\text { et al. }\end{array}$ & $\begin{array}{l}\text { Oooô, "PSORA"! Por } \\
\text { que foi mesmo que a } \\
\text { gente foi lá?: uma } \\
\text { investigação sobre os } \\
\text { objetivos dos } \\
\text { professores ao visitar o } \\
\text { Parque da Ciência } \\
\text { Newton Freire Maia }\end{array}$ & 2009 & $\mathrm{~T} 4$ \\
\hline IX ENPEC & $\begin{array}{l}\text { FABRÍCIO, T. M.; } \\
\text { PEZZO, M. R.; } \\
\text { FREITAS, D. }\end{array}$ & $\begin{array}{l}\text { A cidade como espaço } \\
\text { de educação em } \\
\text { ciências: uma proposta } \\
\text { de ampliação do } \\
\text { potencial educativo de } \\
\text { museus e centros de } \\
\text { ciências a partir do } \\
\text { enfoque CTS }\end{array}$ & 2013 & T5 \\
\hline IX ENPEC & $\begin{array}{l}\text { MONTEIRO, R. S.; } \\
\text { SOUSA, G. G. }\end{array}$ & $\begin{array}{l}\text { Entre a interatividade } \\
\text { cultural e manual nos } \\
\text { museus de ciência e } \\
\text { técnica: de que CTS nos } \\
\text { fala o público? }\end{array}$ & 2013 & T6 \\
\hline
\end{tabular}

Fonte: Autoria própria (2017).

Os artigos A1, A2 e os trabalhos T1 e T2 são de mesma autoria e fizeram parte de uma pesquisa vinculada a um subprojeto intitulado "Ciência, Tecnologia e Sociedade no contexto da alfabetização científica e tecnológica", associado ao projeto "Formação continuada de professores de Ciências: estratégias inovadoras de ensino em espaços formais e não formais de educação", com apoio da Financiadora de Estudos e Projetos (Finep), Museu de Astronomia e Ciências Afins (MAST) e a Faculdade de Educação da Universidade Federal Fluminense, com duração de 1997 a 1999. Todos os trabalhos utilizam como aporte teórico as narrativas e os modos de pensamento de estudantes e professores para apresentar situações de ensino-aprendizagem desenvolvidas em sala de aula e no museu de ciências, em específico no Museu de Astronomia e Ciências Afins (MAST) situado na cidade do Rio de Janeiro. As pesquisas trataram da relação museuescola na perspectiva de práticas que envolvem o movimento CTS e processos de Alfabetização Científica e Tecnológica, e apresentam algumas considerações para a melhoria do Ensino de Ciências.

Para as autoras, a ACT refere-se aos conhecimentos necessários que a sociedade precisa saber sobre CTS em diversos contextos (escola, museu, revistas) e ressaltam que essa maneira de enfocar o Ensino de Ciências já é discutida há muito tempo em países como Inglaterra e Estados Unidos. Para definir alfabetização científica são apresentadas as três dimensões de Shen (1975 apud 
CAZELLI, 1992). Segundo esse estudioso, a primeira dimensão é a prática, que permite aos indivíduos resolverem problemas que exigem apenas conhecimentos básicos; a segunda dimensão, chamada de cívica, remete à consciência construída sobre os problemas e usos da ciência e tecnologia; e a terceira e última é a cultural, formada pelo desenvolvimento de conhecimentos de ciência e tecnologia aprimorados.

Utilizam como referenciais teóricos para discutir as relações CTS alguns críticos ao ensino tradicional, sendo o primeiro deles Ziman (1985), que defende a substituição do ensino tradicional pelo ensino de CTS com a justificativa da possibilidade de construção de uma visão crítica da ciência de forma interdisciplinar. Outra estudiosa citada é Solomon (1993), defensora de um ensino CTS que desenvolve atitudes para solucionar os problemas da utilidade da ciência na sociedade e a compreensão no contexto social.

São destaque os autores Menezes (1988), Zanetic (1989) e Angotti (1991) que há mais de 25 anos já apontavam que os conhecimentos científicos abordados na escola eram descolados entre si e de outras áreas do conhecimento, impossibilitando qualquer relação entre ciência, tecnologia e sociedade. Outros autores citados são Auler, Stueder e Cunha (1997), que desde o final da década de 90, chama atenção à necessidade de uma intervenção curricular, apontando a importância da inclusão de debates CTS na formação inicial e continuada de professores. As autoras desses quatro trabalhos apresentam as ideias de filósofos e sociólogos da Ciência, que defendem os saberes cotidianos para a formação cultural e cidadã dos indivíduos e o movimento CTS como direcionador para o Ensino de Ciências aproximando a ciência do cotidiano.

A metodologia escolhida nas pesquisas foi de caráter exploratório e teve como instrumentos para a constituição dos dados a observação em sala de aula, referente ao uso do material didático produzido pelo MAST; entrevista com professores após o uso desse material; observação de diversas turmas durante visitação ao Museu (Ensino Fundamental I e II). O foco foi investigar como os professores e monitores do museu inseriam o debate CTS em suas intervenções pedagógicas.

A exposição escolhida para as observações nos trabalhos A1 e T2 foi a chamada "Quatro cantos de origem", que mostra o desenvolvimento da ciência e grandes problemas da reflexão humana, delineadas pela ligação entre ciência, tecnologia e sociedade. Foram utilizados inúmeros recursos, desde o teatro, pintura, música até a apresentação de instrumentos científicos como lunetas, espectroscópios, entre outros. Observou-se a dificuldade dos alunos em compreender o modelo geocêntrico, pois este é visto como incorreto na escola, mostrando a falta de tratamento histórico aos temas científicos por parte da educação formal. Já nos trabalhos A2 e T1, a exposição escolhida foi uma de longa duração e que aborda a temática "Tempo".

Destacamos como principal resultado do CTS no ensino formal, onde professores de 1a a 4a série do Ensino Fundamental I relataram que é possível trabalhar essas relações com todos os conteúdos (referindo-se as disciplinas de núcleo comum), já os professores de 5a a $8^{a}$ série identificaram essa relação às disciplinas de ciências e geografia, através da temática ambiental. 
Os trabalhos apontaram três conclusões significativas: i) importância de aprofundar os estudos CTS para o aprimoramento do ensino de ciências; ii) trabalhar o desenvolvimento dos modos de pensamento para demonstrar a utilidade da ciência como processo da cultura e da vida; e iii) distância entre o modo de trabalho da escola e do museu, onde esse último adota uma perspectiva da História da Ciência e a escola não. É apresentado que não existe uma sintonia entre o ensino formal e o não formal, onde o primeiro é apoiado no pensamento paradigmático e o segundo na articulação deste e o pensamento narrativo, proporcionando um aprendizado mais próximo do dia a dia.

As visitas ao museu permitiram uma melhor compreensão dos alunos sobre os temas científicos vistos em sala de aula, ressaltando a importância de se trabalhar na perspectiva CTS estreitando a relação museu/escola. As autoras também concluíram que o fato do museu não necessariamente estar atrelado ao currículo escolar permite abordar uma proposta histórica e contextualizada da ciência de forma a contemplar uma educação com enfoque CTS.

O próximo trabalho analisado, o T3 trata-se de um recorte de uma pesquisa de Mestrado, e foi apresentado no VII Encontro Nacional de Pesquisa em Educação em Ciências no ano de 2009. Teve como objetivo analisar a abordagem das relações entre ciência, tecnologia e sociedade em exposições museográficas de longa duração. As exposições investigadas foram: "Educação Ambiental" do Museu de Ciência e Tecnologia da PUC/RS; "Reprodução e Genética" do Museu da Vida/Fiocruz; e "O planeta Terra e a preservação ambiental" da Estação Ciência/USP.

Utilizando como referencial teórico a educação com enfoque CTS (AIKENHEAD, 1994; AULER, 2002; CEREZO, 1999), comunicação pública da ciência, controvérsia científica e controvérsia nos museus as autoras construíram atributos para mostrar como as relações CTS aparecem nas exposições de museus de ciências. Foram construídos a partir do trabalho de Aikenhead e Ryan (1992 apud CONTIER; MARANDINO, 2009) - Viewson Science-Technology-Society (VOSTS) que teve como objetivo mapear as visões sobre ciência, tecnologia e sociedade de alunos do Ensino Médio.

Três grandes grupos de atributos foram criados, sendo que cada um deles possui subcategorias. Como critério de exemplificação, Contier e Marandino (2009, p. 4) elencaram algumas temáticas apresentadas nas exposições, conforme mostradas a seguir:

i) Atributos relacionados a debates sociais externos à ciência: engloba o impacto social do desenvolvimento de C\&T; resolução de problemas sociais, práticos e cotidianos; questões de cunho ambiental, controversas, éticas; influências políticas do desenvolvimento de C\&T; estímulo à participação do público. Exemplo de temáticas: construção de usinas hidrelétricas e o deslocamento de populações; terapias gênicas; problemas ambientais provocados pela produção de lixo; AIDS; células-tronco; nanociência; exposições onde é possivvel o público emitir e registrar sua opinião.

ii) Atributos relacionados a debates sociais internos à ciência: engloba as características pessoais dos cientistas; coletivização do trabalho científico; procedimentos de consenso; responsabilidade social dos cientistas. Exemplo de temáticas: personagens científicos; o dia a dia de um cientista/pesquisador; a tomada de posição por um cientista renomado sobre determinado assunto polêmico; energia. 
iii) Atributos relacionados a debates históricos e filosóficos: engloba a dimensão histórica e a natureza da ciência. Exemplo de temáticas: construção do conceito científico; natureza do conhecimento científico.

Cabe reforçar aqui, a função política-ideológica da divulgação científica apresentada por Pérez e Moliní (2004), sendo que a atividade científica não é neutra, assim como uma exposição museográfica também não é, onde se espera que o responsável por essa concepção opte implícita ou explicitamente pela democratização da ciência.

Como conclusão do trabalho, as autoras apontam a importância de os três atributos estarem presentes em uma exposição com enfoque CTS e reforçam a necessidade de novas pesquisas que investiguem a educação CTS nos museus, assim como a comunicação pública da ciência.

A pesquisa T4 investigou a relação museu/escola através do entendimento por parte dos professores e alunos do Ensino Médio de escolas públicas e privadas ao visitar um museu de ciências, fazendo o uso de questionários abertos. Os autores afirmaram a importância da visita a um museu ser planejada por parte dos professores junto aos seus alunos, exigindo uma relação de simbiose entre as duas instituições (museu/escola) e o trabalho deve se estender posteriormente a visitação, para que o conhecimento seja realmente resignificado. Como o próprio título anuncia, a pesquisa foi desenvolvida no Parque da Ciência Newton Freire Maia, localizado na cidade de Pinhais no Estado do Paraná.

Um dos aspectos teóricos considerados fundamentais é a discussão no campo da ACT, pois acreditam que os museus de ciências são capazes de reconfigurar a ciência e a tecnologia na população em geral, e em particular, nos estudantes através da inserção de questões ambientais, éticas e políticas da produção científica. Os referenciais teóricos utilizados nessa discussão são Shen (1975 apud LEAL; GOUVÊA, 2002); Lorenzetti \& Delizoicov (2001); e Chiapetta; Sethna; Fillman (1993), afirmando que a alfabetização científica deve ser observada focando quatro vertentes em equilíbrio (conteúdo, natureza investigativa da ciência, entendimento da ciência a partir de seus aspectos históricos e a relação CTS). No questionário aplicado aos professores uma das questões foi "O que você entende por ACT?" e todas as oito respostas foram vagas e incompletas, revelando a necessidade dessa discussão na formação inicial e continuada de professores. Destacamos como conclusão da pesquisa, a urgência de uma sólida parceria entre escola e museu, pois essa última instituição é um espaço riquíssimo de apresentação de novos conhecimentos científicos sendo apresentados de outra forma e que possibilita a promoção da ACT.

O trabalho T5 é de cunho teórico, onde apresenta uma reflexão sobre o potencial educativo dos museus de ciências no que diz respeito ao Ensino de Ciências em uma perspectiva CTS. Os referenciais teóricos trazidos para discutir essa perspectiva são Auler e Bazzo (2001), Santos e Mortimer (2002).

Os autores apresentam uma atividade educativa do Museu de Arqueologia e Paleontologia de Araraquara - MAPA - no Estado de São Paulo. A instituição oferece um "museu a céu aberto", onde os visitantes caminham pelas ruas da cidade e exploram blocos de arenito nos calçamentos, servindo de uma experiência riquíssima e tendo a Paleontologia como papel de destaque no Ensino de Ciências. A principal contribuição do trabalho é no reforço da articulação entre 
os referenciais da educação com enfoque CTS e a integração das práticas formais e não formais de ensino.

O último trabalho analisado T6, apresenta os resultados de uma pesquisa desenvolvida no âmbito do Mestrado de uma das autoras, que teve como objetivo analisar a percepção do público sobre visões críticas e ingênuas das relações CTS em dois espaços de educação não formal. As autoras aproximam suas ideias do PLACTS - Pensamento latino americano sobre Ciência, Tecnologia e Sociedade embasando suas discussões em autores como Angotti e Auth (2001), Auler e Bazzo (2001), Herrera (2003), Dagnino (2003 e 2008) e as abordagens contextualizadas a partir de temas geradores propostos por Paulo Freire.

A pesquisa foi desenvolvida no Museu do Universo, popularmente conhecido como Planetário da Gávea, na cidade do Rio de Janeiro e no Museu de Artes e Ofício, localizado na cidade de Belo Horizonte, no Estado de Minas Gerais. Foram realizadas entrevistas com 58 pessoas, classificadas como público de visitação espontânea e as categorias de análise pautaram-se nas ideias de razão metonímica de Boa Ventura de Sousa Santos e pressupostos do PLACTS.

O trabalho chama a atenção que a maior ocorrência de visões ingênuas das relações CTS pode estar vinculada a um discurso museológico distanciado da construção social da ciência e a emergência de um movimento que se preocupa para a "passagem do encantamento da ciência" para o "interesse pela ciência" (CONTIER, 2009).

Após a leitura dos oito trabalhos selecionados, foi possível identificar aspectos em comum nas investigações realizadas, sendo o primeiro deles a afirmação de que o Ensino de Ciências precisa dispor do enfoque CTS para conseguir promover uma ACT de qualidade, assim como a construção de parcerias sólidas entre museu e escola, pois os museus conseguem transitar por diversas temáticas e alcançar em suas exposições uma educação CTS.

De acordo com Cerati e Marandino (2013) para reivindicar uma educação em museus dentro da perspectiva da ACT é necessário incorporar essas metas em suas exposições, através de: textos críticos; informações com perguntas e respostas relacionadas à ciência e a tecnologia; equipamentos interativos; temáticas controversas; oficinas para a resolução de problemas contemporâneos.

As discussões sobre a promoção da alfabetização científica e tecnológica não podem ficar restritas apenas ao espaço formal de educação, ela deve ir além dos muros da escola. Segundo Cazelli, Marandino e Studart (2003, p. 85) "[...] os museus de ciências, enquanto espaços não formais de educação, pelo trabalho que vem desenvolvendo, adquirem papel inquestionável na ampliação e refinamento do alfabetismo científico".

\section{CONSIDERAÇÕES FINAIS}

O trabalho teve como objetivo identificar, por meio de uma pesquisa documental, as ações educativas ocorridas em museus de ciências com elementos do enfoque Ciência, Tecnologia e Sociedade para a promoção da Alfabetização Científica e Tecnológica. Dentre essas ações, destacamos a oferta de cursos para professores da Educação Básica, reforçando a parceria entre museu e escola (A1, A2, T1, T2); confecção de materiais educativos para serem utilizados no âmbito do 
museu e da sala de aula ( $A 1, A 2, T 1, T 2)$; mapeamento de visões do público visitante de museus sobre CTS (T4, T6); análise de exposições com abordagem CTS, permitindo a realização de avaliação das mesmas e até mesmo a criação de novas (T3); assim como, atividades ofertadas pelos museus que extrapolam os seus muros, explorando a comunidade onde a instituição está inserida (T5).

Todas as ações apresentadas nos trabalhos analisados tiveram como ponto de partida o enfoque CTS para a promoção da ACT, visando propor mudanças no Ensino de Ciências, através de uma abordagem mais crítica, abrindo mão do ensino tradicional e integrando os conhecimentos científicos.

Apesar das discussões sobre CTS já serem realizadas há mais de cinquenta anos, e no âmbito educacional brasileiro a partir do final dos anos 80 , nota-se pouca expressão de tal enfoque no campo do ensino não formal, com uma bibliografia ainda bastante escassa, visto pelo número reduzido de produções encontradas nos principais periódicos e evento da área de Ensino de Ciências.

O número baixo de produções faz jus a própria linha temática de Educação Não Formal e Divulgação Científica, que começou com um crescente nas edições do ENPEC a partir da sexta edição, no ano de 2007 conforme mostra o trabalho de Pscheidt e Lorenzetti (2016), mas que ainda possui poucas produções. No referido trabalho, as produções foram identificadas através de uma busca em todas as Atas do evento (1997-2015), por meio do descritor museu presente no título ou nas palavras-chave. Foi contabilizado um total de 74 trabalhos, sendo que nas últimas quatro edições do evento as produções se mantiveram estáveis, variando entre 15 a 20 trabalhos que discutem o Ensino de Ciências no âmbito dos museus.

Com relação aos estudos identificados em nossa pesquisa, as instituições museais investigadas pelos autores dos trabalhos e artigos estão localizadas na região Sudeste e Sul do Brasil. A região Sudeste do Brasil conta com o maior número de museus e centros de ciências, com destaque para os Estados do Rio de Janeiro e São Paulo. Seu crescimento e fortalecimento, principalmente no período de 2003-2008, foram devido a um incentivo do governo federal através do Ministério da Ciência e Tecnologia e instituições privadas, como a Fundação Vitae e seu programa de apoio aos museus (PAM). Aqui cabe uma reflexão sobre a relação entre tal contexto e a maior representação de pesquisas sobre museus de tal região nos documentos analisados.

Os estudos apresentados tecem considerações significativas e reforçam, assim como Contier e Marandino (2009), a necessidade de novas pesquisas que investiguem a educação CTS nos museus de ciências. Segundo Gouvêa e Leal (2003), as pesquisas no âmbito do ensino de ciências mostram a importância das relações interinstitucionais, como por exemplo, escola/museu/universidade, sendo facilitadoras no processo da alfabetização científica e tecnológica adequada para suprir as demandas exigidas pelo mundo contemporâneo.

Ainda de acordo com as autoras supracitadas, essa relação interinstitucional também pode ser a responsável pela formação continuada de professores, apontada no estudo T2 como uma necessidade no âmbito da ACT. Para Gouvêa e Leal (2003) os educadores não sentem afinidade ao ensinar ciências em razão a deficiência em sua formação ou por não ter currículos que abordem os conhecimentos científicos correlacionados com as questões sociais e políticas. 
Essa escassez de pesquisas do enfoque CTS no âmbito da educação não formal nos mostra que as que se aventuraram a desbravar esse campo de conhecimento em potencial fazem uso de referenciais teóricos da área da educação referentes ao movimento Ciência, Tecnologia e Sociedade, comunicação pública da ciência, questões controvérsias e sociocientíficas para propor e analisar exposições museográficas. De acordo com Contier e Marandino (2010, p. 114) "essa articulação fornece subsídios para analisar as exposições que exploram as relações CTS e as questões de cunho político e sociológico relacionadas ao desenvolvimento da ciência e tecnologia".

Finalizamos destacando a fundamental importância que as instituições que possuem o compromisso com a educação e comunicação da ciência trabalhem com temáticas envolvendo ciência e tecnologia para contribuir com a formação crítica dos cidadãos. Conforme apontado por Contier e Marandino (2010) são necessárias mudanças radicais no currículo das ciências no âmbito formal, assim como nos museus de ciências, aumentando a participação da sociedade na discussão sobre ciência e tecnologia. 


\title{
The Science, Technology and Society approach as a promotion of Scientific and Technological Literacy in Museums of Sciences
}

\begin{abstract}
The aim this work is to identify the educational actions taken in science museums with elements of the Science, Technology and Society (STS) approach to the promotion of Scientific and Technological Literacy (STL). Through a documentary research, papers published in national journals of the area of Science Teaching evaluated with factor A1 and A2 and in the minutes of all the editions of the National Meeting of Research in Education in Sciences - ENPEC were selected. The studies show to the importance of Science Teaching on CTS in order to achieve an effectiveness in ACT and the need to strengthen the relationship between museum and school. Due to the fact that the teaching institutions are unable to provide the public with all the scientific information necessary to Understanding of today's world and science museums to contribute to the critical education of citizens regarding science and technology ( $\&$ \& $)$ issues. We point out the lack of research and the need for reflection and problematization on STS education in the fertile field of science museums.
\end{abstract}

KEYWORDS: STL. STS. Science Museums. Academic Production. 
1 O Programa Qualis é composto por um conjunto de procedimentos utilizados pela CAPES para a estratificação da qualidade da produção intelectual dos Programas de Pós-Graduação (FRANCISCO, 2011). Programa Qualis está disponível em:

<https://sucupira.capes.gov.br/sucupira/public/consultas/coleta/veiculoPublicac aoQualis/listaConsultaGeralPeriodicos.jsf>. Acesso em: 27 de Jan. 2016.

\section{REFERÊNCIAS}

ANGOTTI, J. A. P. Fragmentos e Totalidades do Conhecimento Científico e do Ensino de Ciências. 1991. 364f. Tese (Doutorado em Educação) - Faculdade de Educação, Universidade de São Paulo, São Paulo, 1991.

ANGOTTI, J. A. P.; AUTH, M. A. Ciência e Tecnologia: implicações sociais e o papel da educação. Revista Ciência \& Educação, v. 7, n. 1, p. 15-27, 2001.

AULER, D.; STUEDER, D. M.; CUNHA, M. B. O enfoque ciência-tecnologiasociedade como parâmetro e motivador de alterações curriculares. In: Encontro Nacional de Pesquisa em Educação em Ciências, 1., 1997, Águas de Lindóia. Atas...Águas de Lindóia: ABRAPEC, 1997.

AULER, D.; BAZZO, W. A. Reflexões para a implementação do movimento CTS no contexto educacional brasileiro. Ciência \& Educação, Bauru, v. 7, n. 1, p. 1-13, 2001. Disponível em: http://www.scielo.br/pdf/ciedu/v7n1/01.pdf. Acesso em: 11 abr. 2017.

AULER, D. Interações entre Ciência-Tecnologia-Sociedade no contexto da formação de professores de ciências. 2002. 257f. Tese (Doutorado em Educação Científica e Tecnológica) - Centro de Ciências de Educação, Universidade Federal de Santa Catarina, Florianópolis, 2002.

AULER, D.; DELIZOICOV, D. Ciência-Tecnologia-Sociedade: relações estabelecidas por professores de ciências. Revista Electrónica de Enseñanza de las Ciências, Barcelona, v. 5, n. 2, p. 337-355, 2006. Disponível em: http://reec.uvigo.es/volumenes/volumen5/ART8 Vol5 N2.pdf. Acesso em: 11 abr. 2017.

BAZZO, W. A.; LINSINGEN, I. V.; PEREIRA, L. T. do V. Introdução aos Estudos CTS. Madrid: Organização dos Estados Iberoamericanos, 2003. 
CAZELLI, S. Alfabetização Científica e os Museus Interativos de Ciências. 1992. 163f. Dissertação (Mestrado em Educação) - Departamento de Educação, Pontifícia Universidade Católica do Rio de Janeiro, Rio de Janeiro, 1992.

CAZELLI, S.; FRANCO, C. Alfabetismo Científico: novos desafios no contexto da globalização. Ensaio: pesquisa em educação em ciências, Belo Horizonte, v. 3, n. 1, p. 1-18, 2001. Disponível em: http://www.portal.fae.ufmg.br/seer/index.php/ensaio/article/viewFile/42/75. Acesso em: 11 abr. 2017.

CAZELLI, S.; MARANDINO, M.; STUDART, D. C. Educação e Comunicação em Museus de Ciências: aspectos históricos, pesquisa e prática. In: GOUVÊA, G.; MARANDINO, M.; LEAL, M. C. (Orgs.). Educação e Museu - a construção social do caráter educativo dos museus de ciências. Rio de Janeiro: Access, 2003, p. 83106.

CERATI, T. M.; MARANDINO, M. Alfabetização Científica e Exposições de Museus de Ciências. In: Congresso Internacional sobre Investigación em Didáctica de las Ciencias, 9., 2013, Girona. Disponível em: http://www.geenf.fe.usp.br/v2/wpcontent/uploads/2015/10/art 709.pdf. Acesso em: 13 fev. 2017.

CEREZO, J. A. L. Los estúdios de ciencia, tecnologia y sociedad. Revista Iberoamericana de Educación, n. 20, p. 217-225, 1999.

CHASSOT, A. Alfabetização científica: uma possibilidade para a inclusão social. Revista Brasileira de Educação, Rio de Janeiro, n. 22, p. 89-100, 2003. Disponível em: http://www.scielo.br/pdf/rbedu/n22/n22a09.pdf. Acesso em: 11 abr. 2017.

CHIAPPETTA, E. L.; SETHNA, G. H. \& FILLMAN, D. A. Do middle school life science textbooks provide a balance of scientific literacy themes? Journal of research in science teaching, 30 (7), 787-797, 1993.

CONTIER, D. Relações entre ciência, tecnologia e sociedade em museus de ciências. 2009. 154 f. Dissertação (Mestrado em Educação) - Faculdade de Educação, Universidade de São Paulo, São Paulo, 2009.

CONTIER, D.; MARANDINO, M. Construção de atributos para análise de exposições CTS em museus de ciências. In: Encontro Nacional de Pesquisa em Educação em Ciências, 7., 2009, Florianópolis. Anais... Florianópolis: ABRAPEC, 2009. p. 1-9. 
análise de exposições nos museus de ciências. In: PINTO, G. A. (Org.). Divulgação Científica e Práticas Educativas. Curitiba: CRV, 2010, p. 115-128.

DAGNINO, R. Como ven a América Latina los investigadores de política científica europeus? In: DAGNINO, R.; THOMAS, H. (Org.). Ciência, Tecnologia e Sociedade: uma reflexão latino-americana. Taubaté: Cabral Editora e Livraria Universitária, p. 51-95, 2003.

DAGNINO, R. As trajetórias dos estudos sobre Ciência, Tecnologia e Sociedade e da Política Científica e Tecnológica na Ibero-América. ALEXANDRIA - Revista de Educação em Ciência e Tecnologia, v. 1, n. 2, p. 3-36, 2008.

FABRÍCIO, T. M.; PEZZO, M. R.; FREITAS, D. A cidade como espaço de educação em ciências: uma proposta de ampliação do potencial educativo de museus e centros de ciências a partir do enfoque CTS. In: Encontro Nacional de Pesquisa em Educação em Ciências, 9., 2013, Águas de Lindóia. Anais...Águas de Lindóia: ABRAPEC, 2013. p. 1-7.

FRANCISCO, C. A. Programas de Pós-Graduação em Ensino de Ciências e Matemática no Brasil: análise da produção discente sobre o Ensino de Química (2000-2008). 2011. 305 f. Tese (Doutorado em Ciências) - Departamento de Química, Universidade Federal de São Carlos, São Carlos, 2011.

GOUVÊA, G.; LEAL, M. C. Uma visão comparada do ensino de ciência, tecnologia e sociedade na escola e em um museu de ciência. Ciência \& Educação, Bauru, v. 7, n. 1, p. 67-84, 2001. Disponível em: http://www.scielo.br/pdf/ciedu/v7n1/05.pdf. Acesso em: 11 abr. 2017.

GOUVÊA, G.; LEAL, M. C. Alfabetização Científica e Tecnológica e os Museus de Ciência. In: GOUVÊA, G.; MARANDINO, M.; LEAL, M. C. (Orgs.). Educação e Museu - a construção social do caráter educativo dos museus de ciências. Rio de Janeiro: Access, 2003, p. 221-238.

HERRERA, A. Novo enfoque de desenvolvimento e o papel da ciência e tecnologia. In: DAGNINO, R.; THOMAS, H. (Org.). Ciência, Tecnologia e Sociedade: uma reflexão latino-americana. Taubaté: Cabral Editora e Livraria Universitária, p. 25-45, 2003.

LEAL, M. C.; GOUVÊA, G. Ensino de Ciências e Ciência, Tecnologia e Sociedade: comparando perspectivas no Ensino Formal e Não Formal. In: Encontro Nacional de Pesquisa em Educação em Ciências, 2., 1999, Valinhos. Anais...Valinhos: ABRAPEC, 1999. p. 1-13. 
LEAL, M. C.; GOUVÊA, G. Narrativa, Mito, Ciência e Tecnologia: o Ensino de Ciências na Escola e no Museu. Ensaio: Pesquisa em Educação em Ciências, Belo Horizonte, v. 2, n.1, p. 1-29, 2002. Disponível em:

http://www.scielo.br/pdf/epec/v2n1/1983-2117-epec-2-01-00005.pdf. Acesso em: 11 abr. 2017.

LEAL, M. C.; SOUSA, G. G. Mito, Ciência e Tecnologia no Ensino de Ciências: o tempo na escola e no museu. In: Encontro Nacional de Pesquisa em Educação em Ciências, 1., 1997, Águas de Lindóia. Anais...Águas de Lindóia: ABRAPEC, 1997. p. 1-10.

LORENZETTI, L.; DELIZOICOV, D. Alfabetização Científica no contexto das séries iniciais. Ensaio: Pesquisa em Educação em Ciências, Belo Horizonte, v. 3, n.1, p. 1-17, 2001. Disponível em:

http://www.portal.fae.ufmg.br/seer/index.php/ensaio/article/view/35/66.

Acesso em: 11 abr. 2017.

MENEZES, L. Crise, Cosmos, Vida Humana: Física para uma educação humanista. 1988. Tese (Livre Docência) - Instituto de Física, Universidade de São Paulo, São Paulo, 1988.

MINGUES, E. "O Museu vai à Praia" - Análise de uma ação educativa à luz da Alfabetização Científica. 2014. 395 f. Dissertação (Mestrado em Educação) Faculdade de Educação, Universidade de São Paulo, São Paulo, 2014.

MONTEIRO, R. S.; SOUSA, G.G. Entre a interatividade cultural e manual nos museus de ciência e técnica: de que CTS nos fala o público? In: Encontro Nacional de Pesquisa em Educação em Ciências, 9., 2013, Águas de Lindóia. Anais...Águas de Lindóia: ABRAPEC, 2013. p. 1-8.

NASCIMENTO, S. S. A divulgação das ciências e as instituições patrimoniais. In: PINTO, G. A. (Org.). Divulgação Científica e Práticas Educativas. Curitiba: Editora CRV, 2010, p. 133-147.

PÉREZ, C. A.; MOLINÍ, A. M. V. Consideraciones generales sobre la alfabetización científica em los museos de la ciencia como espacios educativos no formales.

Revista Electrónica de Enseñanza de las Ciencias, v. 3, n. 3, p. 339-362, 2004. Disponível em: http://reec.uvigo.es/volumenes/volumen3/REEC 33 6.pdf. Acesso em: 11 abr. 2017.

PSCHEIDT, C.; LORENZETTI, L. A relação museu e escola nos trabalhos dos ENPECs. In: Simpósio Nacional de Ensino de Ciência e Tecnologia, 5., 2016, Ponta Grossa. Anais... Ponta Grossa: UTFPR, 2016, p. 1-12. 
SANTOS, W. L. P.; MORTIMER, E. F. Uma análise de pressupostos teóricos da abordagem CTS (Ciência-Tecnologia-Sociedade) no contexto da educação brasileira. Ensaio - Pesquisa em Educação em Ciências, Belo Horizonte, v. 2, n. 2, p. 1-23, 2002. Disponível em: http://www.scielo.br/pdf/epec/v2n2/1983-2117epec-2-02-00110.pdf. Acesso em: 11 abr. 2017.

SASSERON, L. H.; CARVALHO, A. M. P. Alfabetização Científica: uma revisão bibliográfica. Investigações em Ensino de Ciências, Porto Alegre, v. 16, n. 1, p. 5977, 2011. Disponível em: http://www.if.ufrgs.br/ienci/artigos/Artigo ID254/v16 n1 a2011.pdf. Acesso em: 11 abr. 2017.

SCHNORR, S. M.; RODRIGUES, C. G. Ciência, Tecnologia e Sociedade na contemporaneidade: implicações educacionais tramadas ao pós-estruturalismo. Revista Brasileira de Ensino de Ciência e Tecnologia, Ponta Grossa, v. 8, n. 3, p. 31-42, 2015. Disponível em: https://periodicos.utfpr.edu.br/rbect/article/view/2062/2178. Acesso em: 11 abr. 2017.

SILVA, L. R. C. da. Pesquisa Documental: alternativa investigativa na formação docente. In: Congresso Nacional de Educação - EDUCERE, 9., 2009, Curitiba. Anais...Curitiba: Pontifícia Universidade Católica, 2009, p. 4554-4566.

SOLOMON, J. Teaching science, Technology and Society. Buckingham, Philadelphia: Open University Press, Coleção Developing Science and Technology Education, 1993.

STRIEDER, R. B. Abordagens CTS na Educação Científica no Brasil: Sentidos e Perspectivas. 2012. 283 f. Tese (Doutorado em Ciências) - Interunidades, Universidade de São Paulo, São Paulo, 2012.

ZANETIC, J. Física também é Cultura. 1989. Tese (Doutorado em Educação) Faculdade de Educação, Universidade de São Paulo, São Paulo, 1989.

ZIMAN, J. Enseñanza y Aprendizage sobre la Ciencia y la Sociedad. México: Fondo de Cultura Economica, 1985.

WOLINSKI, A. E. et al. Oooô, "PSORA"! Por que foi mesmo que a gente foi lá?: uma investigação sobre os objetivos dos professores ao visitar o Parque da Ciência Newton Freire Maia. In: Encontro Nacional de Pesquisa em Educação em Ciências, 7., 2009, Florianópolis. Anais... Florianópolis: ABRAPEC, 2009. p. 1-12. 
Recebido: 29 mai. 2017

Aprovado: 09 set. 2017

DOI: $10.3895 /$ actio.v2n2.6783

Como citar:

PALMIERI, L. J.; SILVA, C. S. da; LORENZETTI, L. O enfoque Ciência, Tecnologia e Sociedade como promoção da Alfabetização Científica e Tecnológica em Museus de Ciências. ACTIO, Curitiba, v. 2, n. 2, p. 21-41, jul./set. 2017. Disponível em: <https://periodicos.utfpr.edu.br/actio>. Acesso em: XXX

Correspondência:

Luciane Jatobá Palmieri

Rua José Duarte de Souza, 127 - Santa Paula - CEP: 13564-030, São Carlos/SP, Brasil.

Direito autoral: Este artigo está licenciado sob os termos da Licença CreativeCommons-Atribuição 4.0

Internacional.

(c) (1) 